\title{
Effect of Deposition Conditions on Oxide Parameters of Silicon
}

\author{
Souad Merabet $^{1 *}$, Ahlem Alioua ${ }^{1}$ \\ ${ }^{1}$ Laboratoire des énergies renouvelables, University of MSB Jijel, Way Ouled Aissa, BP 98, 18000 \\ Jijel, Algeria.
}

\begin{abstract}
In this study, the effect of deposition conditions and the temperature thermal treatment on the oxide parameters of two structures of silicon layers were investigated. The study present the evolution of boron profiles following a dry thermal oxidation in poly-Si $/ \mathrm{SiO}_{2} / \mathrm{c}-\mathrm{Si}$ films deposited at $520^{\circ} \mathrm{C}$ and $605^{\circ} \mathrm{C}$ temperatures and thermally oxidized in dry oxygen at respectively temperature $840^{\circ} \mathrm{C}, 945^{\circ} \mathrm{C}$ and $1050^{\circ} \mathrm{C}$ for $\operatorname{tr}=1 \mathrm{~h} 33$ 'duration. The results show that the deposition conditions and the temperature treatment make a very important impact on the obtained films, which affect the redistribution and localization of dopants. It has been observed that the obtained value of the linear and the parabolic rate constant, the diffusion coefficient and the oxidation thickness are higher in the films deposited at $\mathrm{Td}=520^{\circ} \mathrm{C}$ than those deposited at $\mathrm{Td}=605^{\circ} \mathrm{C}$. Also, the X-ray diffraction is strongly affected by the oxide thickness deposited between poly-silicon layers and crystalline substrates.
\end{abstract}

\section{Introduction}

Thermal oxidation enables the formation of thin, almost defect-free, and reliable silicon oxide films [1]. This is the reason for the dominance of silicon in semiconductor industry compared to other materials [2]. In the last years, particular interest has been given to polycrystalline silicon films and their applications in different area such as microelectronics devices and photovoltaic cells [3]. Oxidation kinetics in poly-silicon is mainly controlled by the presence of grain boundary and the segregation of dopants towards these boundaries [4]. The oxidation of silicon is based on the migration of oxidation species through the already formed silicon oxide layer and following interfacial reactions, described by two parameters, the linear and the parabolic rate constant, respectively [5-7]. These parameters are closely related to the deposition conditions and the initial surface texture of the films.

\section{Layers study}

\footnotetext{
*Corresponding author: s.merabet@univ-jijel.dz
} 
In this work, the effect of the deposition parameters of poly-silicon films obtained by LPCVD method (low pressure chemical vapor deposition), with $200 \mathrm{~nm}$ of thickness and in-situ doped with boron $\left(2 \times 10^{20} \mathrm{~cm}^{-3}\right)$, has been studied as function of the characteristics parameters of thermal oxidation such as the linear and the parabolic rate constant for a thermal treatment at $840^{\circ} \mathrm{C}, 945^{\circ} \mathrm{C}$ and $1050^{\circ} \mathrm{C}$, for duration of $1 \mathrm{~h} 33^{\prime}$. The structure of poly-silicon films has been characterized by X-ray diffraction. The measure X-ray spectra is shown in fig. 1, the XRD intensity exhibit (400) peaks which is the predominant orientation for the deposited poly-silicon films. While the single-crystal substrate was formed according to a $<111>$ crystallographic orientation, this difference is explained by the presence of the interface oxide between the two layers (poly $/ \mathrm{SiO}_{2} / \mathrm{c}-\mathrm{Si}$ ).

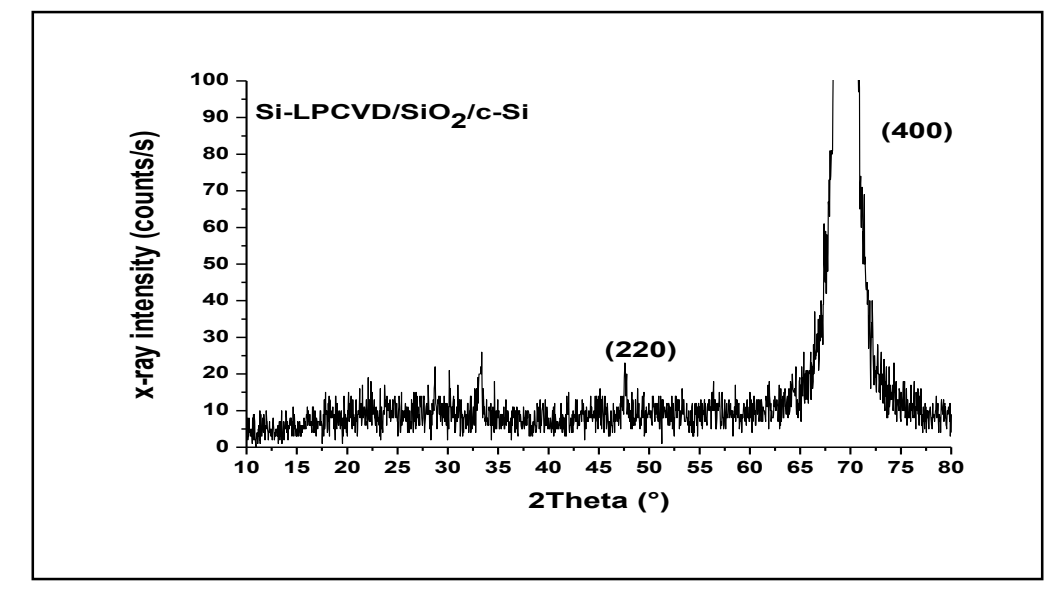

Fig. 1. X-rays diffraction peaks of the poly-silicon layer.

\section{Theoretical model}

The physical mechanism of thermal conductivity in the furnace oxidation is governing by the diffusion of oxidant species in the oxide, and the chemical reactions at the oxidematerial interface. In this case, the kinetic equation is expressed as [8-9]:

$$
X^{2}-\left(X_{0}\right)^{2}+A\left(X-X_{0}\right)=B . t
$$

Where $\mathrm{X}$ is the oxide thickness at time $\mathrm{t}$, and $\mathrm{X}_{0}$ is the oxide thickness at $\mathrm{t}=0 \mathrm{~s}$. And the linear rate constant and the parabolic rate constant are expresses by [10]:

$$
\begin{aligned}
& \frac{B}{A}=C_{1} \times \exp \left(\frac{-E_{1}}{k_{B} T}\right) \\
& B=C_{2} \times \exp \left(\frac{-E_{2}}{k_{B} T}\right)
\end{aligned}
$$

Where $C_{1}(\AA / s)$ and $C_{2}\left(\AA^{2} / s\right)$ are the pre-exponential factors depends on the thermal temperature, the thickness of layer and substrate orientation. $E_{1}$ and $E_{2}$ are activation energies for the linear and the parabolic rate constant respectively. $\mathrm{k}_{\mathrm{B}}$, the Boltzmann constant and $\mathrm{T}$, the oxidation temperature.

The oxide thickness at the thermal oxidation can be described by the solved equation (1), expressed as [10]:

$$
\left.X(t)=\left\{-A(T) \pm \sqrt{A^{2}(T)+4\left[X_{0}^{2}+A(T) \cdot X_{0}+B(T) \cdot t\right.}\right]\right\} / 2
$$




\section{Results and discussion}

Fig. 2 shows the curves of the linear and the parabolic rate constant versus $1 / \mathrm{T}$ for the thermal oxidation temperature range of $840-1050^{\circ} \mathrm{C}$, for two structures of poly-crystalline silicon films with $200 \mathrm{~nm}$ of thickness. The growth rate shows a nearly Arrhenius-like dependence. The activation energies evaluated in curve fitting are $\mathrm{E} 2=1.6 \mathrm{eV}$ for the parabolic rate and $\mathrm{E} 1=2 \mathrm{eV}$ for linear rate respectively.

The linear rate constant is dominated by the reaction at the $\mathrm{SiO}_{2} / \mathrm{Si}$ interface. The results show that the obtained value of the linear rate constant for films deposited at $520^{\circ} \mathrm{C}$ are higher than those obtained for films deposited at $605^{\circ} \mathrm{C}$. This may be explained by the fact that at the interfacial zone, the first $15 \mathrm{~nm}$ thick for films deposited at $520^{\circ} \mathrm{C}$, are amorphous. Under thermal treatment those amorphous regions crystallize, this crystallization is favoured, moreover, by the higher concentration of dopants which segregate at the grain boundary, increases grain size and produces a less rough surface [11]. And the films deposited at $605^{\circ} \mathrm{C}$, are polycrystalline with a small grains [12];

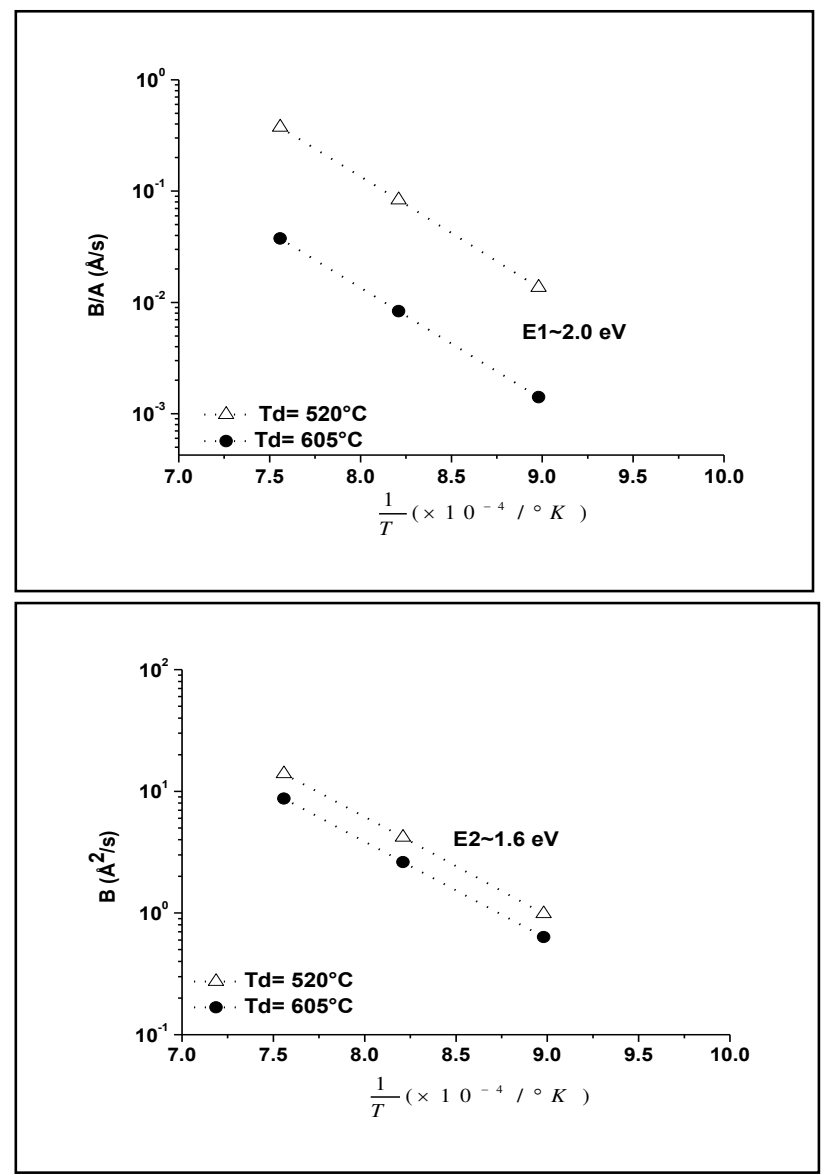

Fig. 2. Arrhenius plot the linear rate constant $(\mathrm{B} / \mathrm{A})$ and the parabolic rate constant $(\mathrm{B})$. The activation energies are calculated to be $\mathrm{E} 1=1.6 \mathrm{eV}$ and $\mathrm{E} 2=2 \mathrm{eV}$. 
In fig. 3, the calculation of oxide thickness was done based on the linear-parabolic oxidation model. The follow-up of the evolution of these curves shows a variation according to the deposition temperature, this can be explained by the different oxidation rate of the grains and the grains boundaries substantially alter the kinetics of oxidation. The oxidation reaction decreases when the crystalline quality of the films increases, with the decrease in the density and disappearance of the deposits intra-granular zones. Also, the difference increase as function of the temperature thermal treatment increase. For $840^{\circ} \mathrm{C}$, $945^{\circ} \mathrm{C}$, and $1050^{\circ} \mathrm{C}$, the difference is $100 \AA, 200 \AA$ and $300 \AA$ respectively.

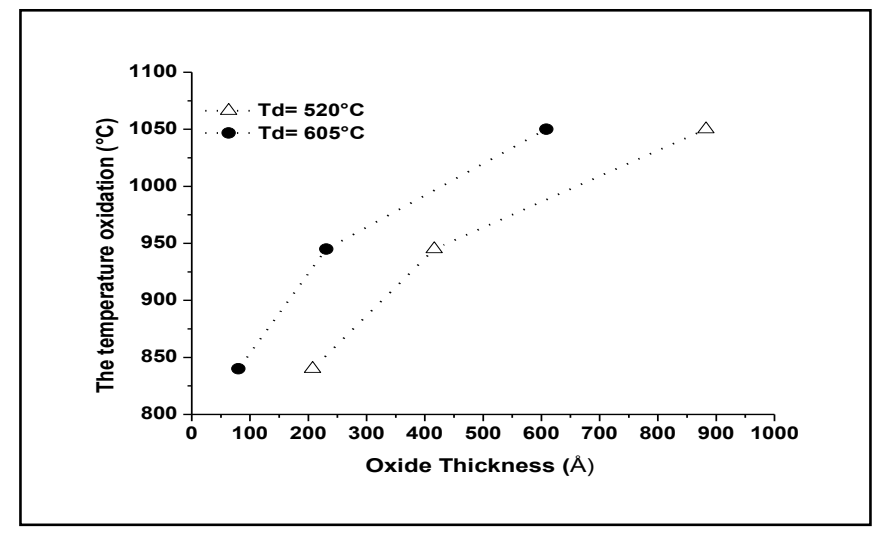

Fig. 3. Relationship of oxide thickness and deposition temperature

In order to examine the relationship between the effect of the dry thermal oxidation and the structure of the films, the in-situ boron diffusion coefficient $\mathrm{D}$ was estimated by modelling the profiles in fig. 4. The dopants will follow the limited-source diffusion process, which is governed by the following equation [13]:

$$
C(x, t)=C_{0}(O, t) \cdot \exp \left[-\left(\frac{x}{2 \sqrt{D t}}\right)^{2}\right]
$$

Where $C_{0}, x$, and $t$ represent the initial surface concentration, the diffusion distance, and the annealing time respectively;

(a)

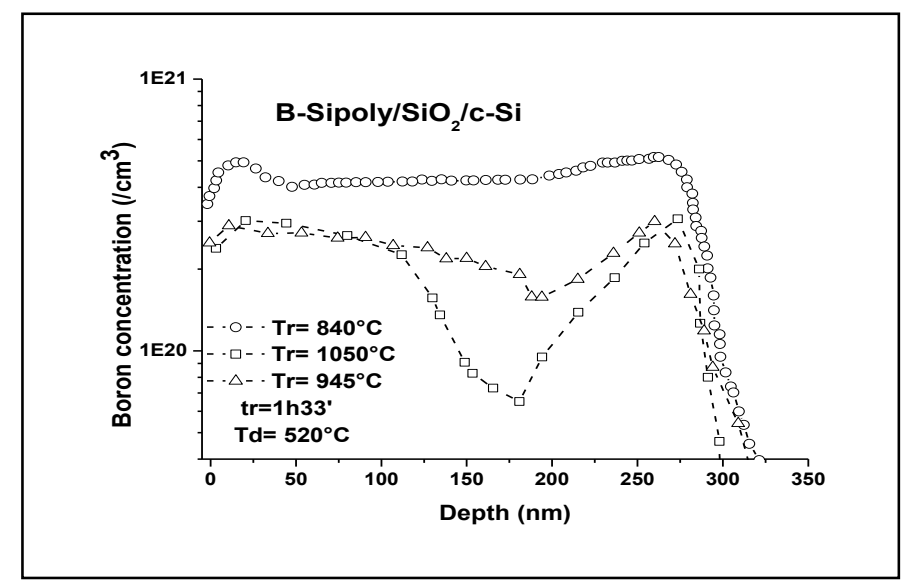


(b)

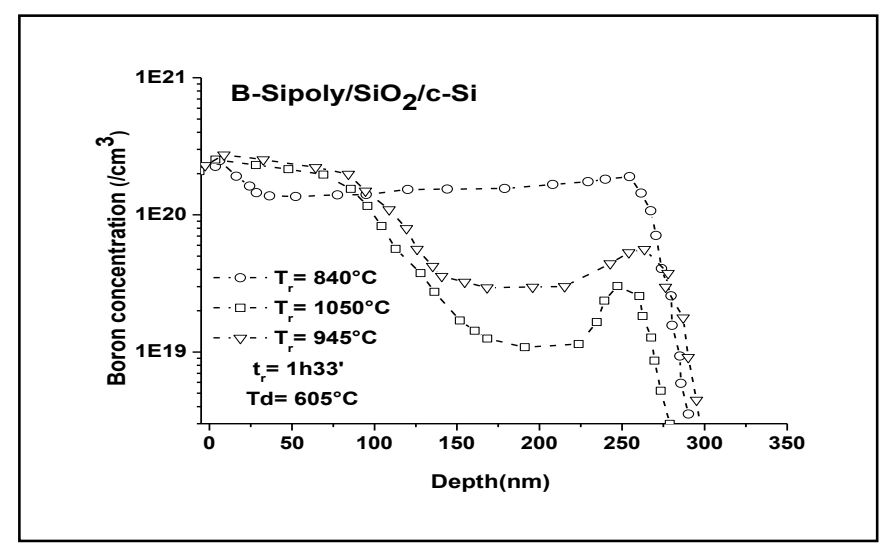

Fig. 4. Experimental boron profiles after treatment annealing, (a) $\mathrm{Td}=520^{\circ} \mathrm{C}$ and (b) $\mathrm{Td}=605^{\circ} \mathrm{C}$.

The obtained results of the diffusion coefficient are illustrated in fig. 5. The follow-up of the evolution of these results shows a variation according to the temperature treatment, from $840^{\circ} \mathrm{C}$ to $1050^{\circ} \mathrm{C}$, with clear increase starting from the temperature treatment of $1050^{\circ} \mathrm{C}$. Just a small variation is observed when the obtained values are compared in the two structures, but at $1050^{\circ} \mathrm{C}$ the results are approximately the same. This can be explained by the fact that the structures under high levels of doping and heat treatment evolve to the same morphological structure. The same results were observed for different durations of treatment in other works [14-15].

According to the results in fig. 5, the variation of estimated diffusivities versus the temperature reverse enables to calculate with the Arrhenius expression low, the value of activation energy [16]:

$$
D=D_{0} \cdot \exp \left(\frac{-E_{a}}{k_{B} \cdot T_{o x}}\right)
$$

Where $D_{0}, k_{B}$, and $T_{o x}$ represent the pre-exponential diffusion coefficient, the Boltzmann constant, and the annealing temperature, respectively;

The evaluated activation energies in curve fitting are $\mathrm{Ea}=2.32 \mathrm{eV}$ and $\mathrm{Ea}=2.056 \mathrm{eV}$ for the films deposited at $520^{\circ} \mathrm{C}$ and $605^{\circ} \mathrm{C}$ respectively. Previous results reported by $[11,14]$, showed a good agreement with those values.

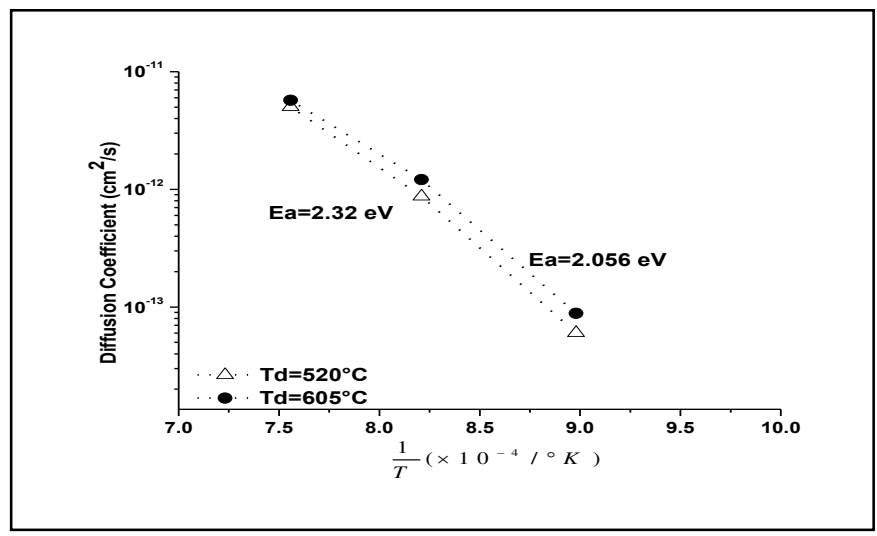

Fig. 5. Relationship of diffusion coefficient and oxidation temperature. 


\section{Conclusion}

In this work, we have examined the dry oxidation of poly-Si/SiO${ }_{2} / \mathrm{c}-\mathrm{Si}$ layers deposited through LPCVD and doped in-situ with boron. The structure of layer affect the localization and redistribution of dopant, it has been found that the value of the diffusion coefficient is more important in the layer deposited at $520^{\circ} \mathrm{C}$ than the layer deposited at $605^{\circ} \mathrm{C}$ for several temperatures treatment, and for the higher temperature treatment $\left(1050^{\circ} \mathrm{C}\right)$ just a very small variation is observed between the two structures. The results are approximately in accord; this was explained by evolve structures under higher thermal treatment in the same structural morphologies.

At the same, the obtained results showed that the oxidation parameters (the linear and the parabolic rate constant) were dependent on the deposition conditions (deposition temperature) and the heat treatment temperature. Subsequently, these results were confirmed by the formed oxide thicknesses in each layer.

The authors would like to thank Mr. M. Boukezzata for his services. This work has been supported by ministry of higher education and scientific research of Algeria.

\section{References}

1. G. Gerlach, k. Maser, Ad. cond. Mat. Phys, Article ID 7545632 (2016)

2. B. Lojek, Historiy of semiconductor Engineering, Springer, Berlin, Germany (2005)

3. D. Sandor, S. Fulton, J. Engel-Cox, C. Peck and S. Peterson, J. Sustainability 10(1), 160 (2018)

4. J. Yun, J. Huang, A. Teal, K. Kin, S. Varlamov and M. A. Green, J. Thin Solid Films, 609 pp.12-18 (2016)

5. H. Fukuda, J. Applied Surface Science, 113-114 pp.595-599 (1997)

6. U. Hashim et al, Comparison of Deal Grove Model growth rate with Dry thermal oxidation process for ultra-thin Silicon Dioxide film, Conference paper, DOI: 10.1109/COBE.2015 (2015)

7. G. Kovacevic, B. Pivac, J. Appl. Phys, vol. 115, n4, Article ID 043531(2014)

8. A. Hemeryck, Modélisation à l'échelle atomique des premiers stades de l'oxydation du silicium: Théorie de la Fonctionnelle de la Densité et Monte Carlo cinétique, Doctorate thesis, Université Toulouse III - Paul Sabatier (2008)

9. R. Fabien, Study of Thermal Oxidation of SiGe for Advanced CMOS FD-SOI Technologies, Doctorate thesis, Université de Grenoble Alpes (2018)

10. H. Fukuda, M. Yasuda and T. Iwabuchi, J. Appl. Phys. Vol. 31 pp.3436-3439 (1992)

11. M. Lemiti, S. Audisio, C. Mai, B. Balland, Revue Phys. Appl. 24 pp.133-141(1989)

12. S. Merabet, B. Birouk, J. Hydrogen Energy. Vol. 42, I 48 pp.29026-29032 (2017)

13. B. Guan et al., Scientific Reports | 5:12641 | DOI: 10.1038/srep12641(2015)

14. M. Boukezzata, B. Birouk, F. Mansour, D. Bielle-Daspet, J. Chem. Vap. Dep. vol. 3, $\mathrm{n}^{\circ} 5$, pp.271-279 (1997)

15. E. T. Seid and F. B. Dejene, Optical Materials Express. vol.10, n¹1, pp.2849-2865 (2020) 